\title{
Discussion \\ Processing discontinuous lexical items: a reply to Frazier
}

\author{
Gerard Kempen \\ Experimental and Theoretical Psychology Unit, Rijks Universiteit Leiden, \\ Pieter de la Court Building, Wassenaarseweg 52, 2300 RB Leiden, Netherlands
}

1. In my comment (Kempen, 1995) on the original Frazier, Flores d'Arcais, and Coolen (1993; henceforth FFC) study, I pointed out that the control condition was inadequate due to the inadvertent inclusion of separable complex verbs in the sentence materials for the control condition. I gave aanhebben as an example. In her response, Frazier (1995) admits this oversight but adds that it works against the experimental prediction and therefore does not weaken the theoretical conclusions drawn from the data. She would be right if only a small proportion of the 12 control sentences suffered from this handicap. As a matter of fact, the problem resides not just in the seven control sentences with aan +hebben, but in the five remaining ones as well. The prepositions voor, om and bij occurring in the latter sentences all form separable complex verbs with hebben, as is easily verified; for example, by consulting a recent edition of the authoritative Van Dale Groot Woordenboek der Nederlandse Taal. I conclude there was no control condition at all.

2. In an attempt to rescue FFC's theoretical interpretation, Frazier then makes the additional assumption of a "bias in processing for a closed class interpretation of items homophonous between a closed class (e.g., auxiliary) and an open class (e.g., main verb) analysis". Hebben indeed is ambiguous between an auxiliary and a main verb, like the English verb to have. The hypothetical bias will cause the lexical processor to analyze hebben as an auxiliary. This precludes a complex verb reading with aan, voor, om, etc., and protects the perceivers against a lexical garden path in the control sentences. In support of this closed class bias, Frazier cites an experiment by Shillcock and Bard (1993), who observed that the auxiliary would in a sentence like John said that he didn't want to do the job, but his brother would... did not prime timber, a word semantically related to the homophonous open class item wood. However, this bias towards a closed class analysis of would/wood only obtained in a syntactic context that ruled out the presence of a noun. Context effects of this type cannot have 
occurred in FFC's sentences. A fragment like Aan wie heb je... readily admits a main verb interpretation of heb. For instance, Aan wie heb je een hekel? is a perfectly normal Dutch sentence (who do you hate? Literally: to whom do you have a dislike?); additional examples with other prepositions are easy to find.

Actually, Shillcock and Bard interpret their result as showing that lexical access to closed class items is sensitive to syntactic constraints. This contradicts the position defended by FFC in the first place, namely, that the lexical processor is an autonomous module producing its output uninformed by the results of syntactic processing. I see no reason to assume that closed class analyses were given priority and conclude that the rescue operation fails.

3. At the end of her response, Frazier invites me to come up with an alternative account of the FFC data. I will concentrate on the critical interaction between sentence form (NP-initial vs. PP-initial; e.g., Wie . . vs. Aan wie...) and tense (simple vs. complex; e.g., bied je ... aan vs. heb je... aangeboden). The most salient data point is the very long RT for NP-initial complex tense sentences; for example, Wie heb je nu de dranken aangeboden? What makes this condition so difficult in comparison with its three counterparts?

A possible explanation is the following. While dealing with this sentence, the syntactic processor experiences a great deal of uncertainty with respect to the grammatical role it needs to assign to each of the incoming NPs in this structure. This applies irrespective of whether hebben is seen as main verb or as auxiliary. Only NP2, personal pronoun je (you), can be analysed forthwith as the subject, by virtue of its position immediately after the second-person verbform heb. NP1 and NP3, however, find little to hold on to until the very last word of the sentence. Direct object and indirect object are candidate roles for NP1 and NP3; NP3 can also serve as object of a subsequent preposition (or, rather, postposition; cf. Wie heb je gister het huis uitgezet? Who have you evicted yesterday? Literally: who have you yesterday the home out-of-put. Here, uit is a postposition governing the NP het huis). This uncertainty remains until aangeboden has been recognized as the main verb. To make things even worse, NP1 and NP3 may serve various functions in embedded clauses, as in Wie heb je de dranken zien aanbieden? (Who have you seen offering the drinks?), where wie is the subject of an infinitival complement clause headed by aanbieden. The PP-initial counterpart of this sentence creates considerably less uncertainty because aan wie can be analyzed right away as a modifier phrase (probably interpretable as beneficiary or locative).

This reasoning also explains why, in the English-language experiment, the NP-initial present tense sentences did not present a particular problem: their NP3 always follows the main verb and is immediately analyzable as direct object. I hasten to add, though, that this cannot be the whole story - other factors must have been at work as well. 
4. In sum, the sentences used in the control conditions of FFC's Dutchlanguage experiment are unsuited for their purpose because they all include separable complex verbs, just as the experimental sentences do. Frazier's theoretical argument that the complex verbs in the control conditions cannot have been interpreted as main verbs but only as auxiliaries is incompatible with FFC's original position and cannot rescue the experiment. The essential part of FFC's data does not seem to require an account in terms of autonomous lexical and syntactic processors; known properties of syntactic processing alone can provide a plausible explanation.

\section{References}

Frazier, L. (1995). Processing discontinuous lexical items, by whatever name. Cognition, 54, $357-359$.

Frazier, L., Flores d'Arcais, G.B., \& Coolen, R. (1993). Processing discontinuous words: on the interface between lexical and syntactic processing. Cognition, 47, 219-249.

Kempen, G. (1995). Processing separable complex verbs in Dutch: comments on Frazier, Flores d'Arcais, and Coolen (1993). Cognition, 54, 353-356.

Shillcock, R., \& Bard, E.G. (1993). Modularity and the processing of closed-class words. In G. Altmann \& R. Shillcock (Eds.), Cognitive models of speech processing. Hillsdale NJ: Erlbaum. 